\title{
Ensinando Subtração para Pessoas com Deficiência Mental com Base em Relações de Equivalência de Estímulos ${ }^{1}$
}

\author{
Priscila Mara de Araújoº \\ Escola Superior de Tecnologia e Educação de Porto Ferreira \\ Paulo Roberto dos Santos Ferreira \\ Universidade Federal de São Carlos
}

\begin{abstract}
RESUMO - Foi avaliado um procedimento para o ensino de subtração a indivíduos deficientes mentais, por meio de relações ambientadas em tarefas de MTS. O primeiro passo consistiu nos testes das relações da classe ABC (relações quantitativas de 1 a 9) e FGH (operadores menos e igual). O segundo consistiu nos testes/treinos das relações entre as sentenças da classe IJK - falada (I), com conjuntos (J) e com algarismos $(\mathrm{K})$ - para os valores de um a cinco. O terceiro passo consistiu nos treinos/ testes, com valores de $u m$ a nove, das relações entre a sentença (classe IJK) e o resultado (classe ABC). Ao final, verificou-se a emergência de algumas relações em sessões de teste, sugerindo potencialidade para a aquisição de responder adequado a novas combinações de estímulos numéricos. Contudo, testes em outras populações e com outras operações aritméticas são necessários para analisar a aplicabilidade do programa no ensino de operações matemáticas.
\end{abstract}

Palavras-chave: equivalência de estímulos; subtração; deficientes mentais; análise experimental do comportamento.

\section{Teaching Subtraction for Individuals with Mental Retardation Based on Stimulus Equivalence Relations}

\begin{abstract}
A MTS procedure to teach subtractions involving equivalence class formation nets was evaluated to teach people with mental retardation. The first step was the tests of the relations involved in the subtraction operation - numerals from 1 to 9 (class $A B C)$ and operators that composed the operation (class FGH). The second comprised tests/training of the relations between the sentences - spoken $(\mathrm{I})$, with sets $(\mathrm{J})$ and with algorisms $(\mathrm{K})$ - to values from 1 to 5 . The third step consisted on the training/tests of the relation between sentence (class IJK) and result (class ABC), to values from 1 to 9 . The results showed that the procedure allowed the emergency of some relations in test sessions, suggesting its potentiality to the acquisition of adequate responding to new numerical stimuli combination. It is considered that the procedure must be tested in other populations using, besides mathematic, other arithmetic operations.
\end{abstract}

Key words: stimulus equivalence; subtraction; mental retardation; experimental analysis of behavior.

O trabalho, como importante promotor da inclusão de pessoas deficientes mentais na sociedade, demanda a aquisição de um repertório mínimo de comportamentos matemáticos. Um repertório aritmético básico é, por conseguinte, pré-requisito indispensável para a realização de tarefas acadêmicas e não-acadêmicas e para atividades de mensuração e de trabalho (Spradlin, Cotter, Stevens \& Friedman, 1974). Esse repertório inclui, entre outros comportamentos aritméticos, o de realizar subtrações, sem o qual o trabalho e, portanto, a autonomia do indivíduo deficiente mental, ficam comprometidos.

A análise experimental do comportamento, especialmente ao se ocupar do fenômeno de formação de classes de estímulos equivalentes, coloca-se como uma importante alternativa ao ensino de habilidades acadêmicas, à medida que tem contribuído para a produção de procedimentos eficazes para

1 O trabalho é derivado da dissertação de mestrado defendida pelo primeiro autor no Programa de Pós-Graduação em Educação Especial - UFSCar, motivo pelo qual agradece a orientação do Prof. Dr. Celso Goyos e ao apoio financeiro parcial concedido pela CAPES.

2 Endereço: Rua Carlos Fenilli, 439, Vila Salgueiro, Porto Ferreira, SP, Brasil 13606-970. E-mail: pri_psy@yahoo.com.br/araujo_priscila@ hotmail.com. o ensino de comportamentos matemáticos a crianças com desenvolvimento cognitivo típico e pessoas com deficiência mental (Figueiredo, Silva, Soares \& Barros, 2001; Kahhale, 1993; Prado \& de Rose, 1999; Rossit, 2004; Spradlin \& cols., 1974; Stoddard, Bradley \& McIlvane, 1987; Stoddard, Brown, Hurlbert, Manoli \& McIlvane, 1989).

O paradigma de equivalência de estímulos consiste na sistematização de procedimentos de ensino e de avaliação da formação de classes de estímulos equivalentes (Sidman, 2000). Os estímulos integrantes das classes são, por definição, intercambiáveis em determinados contextos, comumente aqueles caracterizados por tarefas de escolha de acordo com o modelo (MTS, do inglês matching-to-sample). Essa característica implica no emprego do paradigma ao se estudar comportamentos simbólicos do tipo referentesímbolo, em que os estímulos das classes funcionam como símbolos e referentes uns dos outros, dependendo da relação entre estímulos que estiver sendo exibida (Sidman, 1994). A tecnologia proveniente é representada principalmente pelo procedimento de escolha de acordo com o modelo (MTS), eficaz no estabelecimento de relações arbitrárias e empregado pioneiramente na formação de classes equivalentes por Sidman (1971). 
O procedimento de MTS ocorre quando, dados pelo menos dois estímulos, B1 e B2, é requerido que o sujeito selecione B1 sob controle do estímulo condicional A1 e selecione B2 sob controle do estímulo condicional A2. Os estímulos exemplificados B1 e B2 são usualmente denominados de "escolhas", ou estímulos discriminativos, enquanto A1 e A2 são denominados de "modelos", ou estímulos condicionais. Por exemplo, dados dois números, um e cinco: na presença do numeral escrito "UM", é requerido que o sujeito escolha o algarismo impresso " 1 ", enquanto que na presença do numeral escrito "CINCO”, é requerido dele a escolha do algarismo impresso "5". A relação entre o modelo e a escolha é estabelecida por meio de reforçamento e é qualificada como discriminação condicional (Sidman, 1994).

De León (1998) obteve a instalação, por meio de tarefas de MTS envolvendo os números de um a seis, de repertórios matemáticos básicos, além da formação de classes equivalentes envolvendo os mesmos estímulos em um delineamento inter-grupos, com crianças pré-escolares. O estudo lidou com dois grupos experimentais e um grupo controle. As relações ensinadas para cada grupo experimental foram testadas para o outro e vice-versa. Os estímulos foram numerais ditados, símbolos numéricos impressos e conjuntos. As respostas foram contagem, nomeação e apontar em tarefas de MTS. O Grupo 1 teve como treino as relações entre estímulos numerais auditivos e conjuntos ou numerais impressos em contexto de MTS, ao mesmo tempo em que o Grupo 2 teve como treino a contagem dos conjuntos e a nomeação dos numerais impressos. Os resultados mostraram que, apesar de todos os participantes dos grupos experimentais aprenderem todas as relações, o Grupo 1 foi o que obteve os melhores resultados em um número menor de sessões de treino. O Grupo controle, como era de se esperar, não aprendeu nenhuma das relações.

Prado e de Rose (1999) consideraram que seria possível conceber o conceito de número como uma rede de relações estímulo-estímulo e/ou estímulo-resposta, das quais algumas são aprendidas por meio de ensino direto e outras por emergência comportamental. Utilizando uma adaptação do diagrama de Sidman (1971), Prado e de Rose (1999) analisaram habilidades pré-aritméticas na perspectiva de rede de relações, sugerindo que o modelo facilita a tomada de decisões sobre quais estratégias de ensino utilizar com determinado aluno, já que especifica com exatidão as relações inexistentes em cada repertório (Prado \& de Rose, 1999).

Participaram do estudo de Prado e de Rose (1999) crianças com idade entre 3 e 7 anos e uma adolescente com Sindrome de Down com 16 anos de idade. O estudo foi dividido em três passos sem critério para mudanças de fases, considerando que o estudo consistiu unicamente de avaliações, sem ensino das relações testadas. Os estímulos utilizados foram numeral ditado, numeral impresso e conjuntos em uma variedade de disposições, tamanhos, formas e quantidades. As respostas foram apontar, nomear e contar. Testaram-se as relações entre numerais ditados e numerais impressos e conjuntos, e entre a nomeação dos numerais impressos e contagem dos conjuntos. O procedimento utilizado permitiu que os repertórios dos sujeitos fossem avaliados, verificando-se quais relações estavam presentes e quais ainda necessitariam ser treinadas. $\mathrm{O}$ trabalho realizado possibilitou que habilidades pré-aritméticas fossem analisadas na perspectiva de rede de relações, o que pode facilitar a tomada de decisões sobre quais estratégias de ensino utilizar com determinado aluno (Prado \& de Rose, 1999).

De León (1998) e Prado e de Rose (1999) tiveram como objetivo analisar como o conceito de número pode ser definido comportamentalmente com base nas relações estabelecidas entre estímulos numéricos. Mas as relações entre numerais e conjuntos (quantidades) podem ser consideradas um prérequisito para o ensino de habilidades aritméticas de soma e subtração? Serão as habilidades aritméticas complementares ao conceito de número? Em suma, trata-se de saber se as relações entre estímulos numéricos são suficientes quando se trata de explicar não somente o conceito de número, mas também o estabelecimento de repertórios comportamentais característicos das operações matemáticas, tais como as de subtração e de adição. É possível que questões como essas ainda necessitem de um certo número de investigações científicas para serem adequadamente respondidas.

Resnick, Wang e Kaplan (1973) definiram que a subtração envolve o conceito de partição de conjuntos e compõese com base em alguns objetivos. O operante "subtrair", nesse sentido, deve se referir aos comportamentos que, controlados por estímulos numéricos complexos, produzam estímulos numéricos que correspondam ao que entendemos matematicamente como o resultado da subtração. Sendo assim, os objetivos elencados pelos referidos autores são, em seqüência hierárquica: a) Dados dois números, conjuntos de objetos e instruções para subtrair, a criança pode tirar o menor subconjunto do maior e expor o restante; b) Dados dois números escritos em forma linear e instruções para subtrair, a criança pode usar os números alinhados para subtrair e determinar o resultado; c) Dados problemas de subtração com palavras, a criança pode solucionar os problemas; d) Dados problemas escritos de subtração na forma gráfica (em que há um numeral sobre o outro e um traço abaixo mais o traço de igual) a criança pode completá-los corretamente; e) Dados problemas de subtração na forma $x-y=\square$, a criança pode completar as equações.

Resnick e cols. (1973) inseriram o ensino de subtração na parte introdutória de um currículo de matemática, o que, segundo eles, auxilia a criança a ampliar e estabilizar os conceitos de conjunto e número, preparando-a para um estágio mais avançado do entendimento matemático. Levando em conta a hierarquia dos objetivos, Resnick e cols. (1973) sugerem ainda que as tarefas que utilizam os números em forma linear são mais complexas do que as que utilizam conjuntos de objetos. É importante notar, no entanto, que para muitas crianças, as sentenças escritas podem ser a melhor forma de dar instruções dentro de objetivos específicos, e tais formas de subtração podem ser aprendidas simultaneamente com o uso dos conjuntos de objetos, tornando-se as sentenças com conjuntos de objetos equivalentes às sentenças com algarismos.

Diante da importância do tema, o presente estudo teve como objetivo ensinar relações de subtração para pessoas com deficiência mental e analisar o papel da variável independente treino de relações entre estímulos numéricos para o estabelecimento de relações funcionais entre os estímulos envolvidos, tais como as partes estruturais que compõem a sentença matemática - conjuntos de objetos, algarismos, 
operadores de subtração - e as respostas discriminadas dos participantes, que são as variáveis dependentes medidas no presente estudo. De um modo geral, tratou-se da avaliação de um procedimento de ensino baseado no paradigma de equivalência de estímulos.

\section{Método}

\section{Participantes}

Os participantes foram três pessoas com deficiência mental, com idades entre 15 e 35 anos, estudantes em período parcial de uma escola de educação especial. Todos possuíam experiência prévia em tarefas no contexto de MTS realizadas no computador e demonstravam repertório verbal bom, com capacidade para entender tanto as instruções fornecidas pela experimentadora quanto pelo computador. A Tabela 1 caracteriza os participantes.

O presente estudo foi aprovado pelo Comitê de Ética da Universidade Federal de São Carlos, instituição à qual eram filiados os autores, o que incluiu o reconhecimento de que o TCLE (Termo de Consentimento Livre e Esclarecido) estava de acordo com o que determina a Resolução 196/96 de 1996 do Conselho Nacional de Saúde, especificando, dentre outras coisas, os objetivos e condições de realização do estudo, esclarecimentos sobre o direito ao sigilo de identificação, informações sobre o estudo e a interrupção da participação e riscos à integridade física, moral, emocional e cognitiva da criança.

\section{Material e ambiente experimental}

Foram utilizados um microcomputador Apple Performa 6360 com monitor colorido, kit multimídia e um dispositivo formado por um tubo de PVC com aproximadamente $30 \mathrm{~cm}$ de comprimento, sustentado por um tripé. Por uma das extremidades do tubo eram introduzidas fichas e, na extremidade oposta, foi colocado um copo de acrílico transparente, como recipiente para as fichas. Foi utilizado, também, um gravador, com a finalidade de registrar as falas durante os testes de nomeação para posterior cálculo de fidedignidade. $\mathrm{O}$ ambiente experimental foi montado numa sala da escola.

\section{Estímulos experimentais}

Os estímulos empregados para os números de um a nove foram algarismos impressos (“1”, “2”, “3”, “4”, “5”, “6”, “7”, "8" e "9"), sentenças de subtração impressas (p. ex. "2 - 1=") e ditadas (p. ex. /dois menos um igual a/), numerais ditados (p. ex. /um/, /dois/, etc.), conjuntos de bolinhas representando as operações de subtração e seus resultados, operadores mais, menos e igual ditados (/mais/, /menos/ e /igual/) e impressos ( “+”, “-“, e "=") e palavras impressas correspondentes aos operadores ("MAIS", "MENOS" e "IGUAL").

Os estímulos foram apresentados pelo computador em um quadrado branco sobre um fundo azul, medindo $4 \mathrm{~cm}$ $\mathrm{x} 4 \mathrm{~cm}$, sendo as bolinhas apresentadas em cor vinho e os operadores, algarismos e palavras em cor preta, tendo como fontes os algarismos em Times 110, os operadores em Times New Roman 70 e as palavras correspondentes aos operadores em Verdana 35. As bolinhas que compuseram os conjuntos tinham aproximadamente oito milímetros de diâmetro cada.

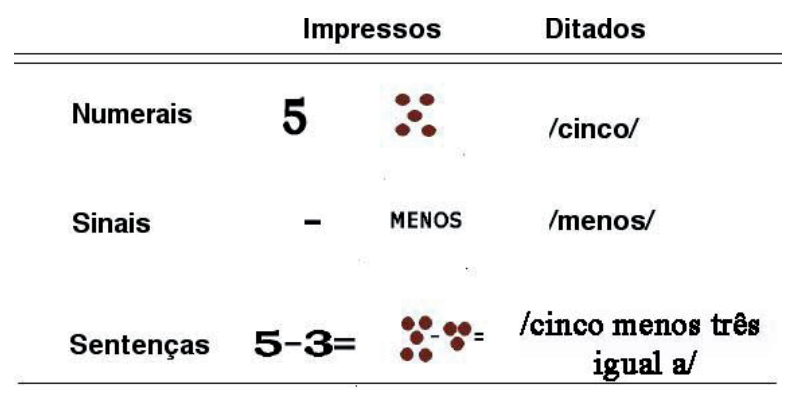

Figura 1. Exemplos dos estímulos experimentais utilizados no estudo. A Figura 1 exemplifica os estímulos utilizados no estudo.

\section{Procedimento geral}

As tarefas foram elaboradas por meio do procedimento de escolha de acordo com o modelo (MTS). Os estímulos foram organizados em tentativas do tipo auditivo-visual e visualvisual. Nas tentativas do tipo auditivo-visual, o computador ditava o estímulo-modelo, que podia ser um número (por exemplo, /dois/), ou um operador matemático (por exemplo, /menos/), ou uma sentença de subtração (por exemplo, /dois menos um igual a/), enquanto na metade superior da tela do monitor aparecia um quadrado branco. O participante foi instruído a tocar o quadrado quando ouvisse a(s) palavra(s) ditada(s) pelo computador. Com o toque do participante no quadrado, seguido de um click com o mouse sobre o mesmo por parte da experimentadora, dois ou três estímulos de escolha, que podiam ser algarismos impressos, operadores impressos, conjuntos de bolinhas, sentenças impressas com algarismos ou com conjuntos ou ainda palavras impressas referentes aos operadores eram imediatamente (MTS com atraso zero) apresentados na metade inferior da tela. Então, o participante deveria escolher o estímulo correspondente ao modelo, tocando-o.

Tabela 1. Caracterização dos participantes, incluindo idade, sexo, diagnóstico de deficiência mental, idade mental avaliada e pontuação obtida em avaliação por meio do instrumento WISC realizada antes do início do estudo.

\begin{tabular}{lllllll}
\hline Participante & Idade $(*)$ & Sexo & Diagnóstico & I.Mental $(*)$ & Q.I. & Classificação \\
\hline MRO & & & & & WISC $(* *)$ & Moderada \\
DUD & 35 & F & D.A. e D.M. & 10,6 & 54 & Moderada \\
ROD & 17 & M & D.M. & 5,1 & 41 & Moderada \\
\hline
\end{tabular}

Nota: *Anos, ** Escala Wechsler de Inteligência para Crianças (aplicado em 2000), D. A.: Deficiência Auditiva, D. M.: Deficiência Mental, Q.I.: Quociente de Inteligência, I. Mental - Idade Mental. 
Tabela 2. Delineamento experimental - sequiência das relações de treinos e testes com os estímulos utilizados em cada uma das fases, o número de tentativas e o critério para mudança de uma fase para outra do procedimento.

\begin{tabular}{llll}
\hline Delineamento experimental & Valores utilizados & Número de tentativas & Critério* (\% acertos) \\
\hline 1. Pré-teste geral & Um a nove e operadores mais, menos e igual & 162 & - \\
2. Treinos do passo 1 & Um a nove e operadores menos e igual & 21 & 100 \\
3. Testes de simetria, transitividade e nomeação & Um a nove e operadores mais, menos e igual & 48 & - \\
4. Pré-testes específicos entre as sentenças (falada, & Um a nove & 72 & - \\
com conjuntos e com algarismos) & Um a cinco & 9 & 100 \\
5. Treinos do Passo 2 & Um a cinco & 20 & - \\
6. Testes de simetria, transitividade e nomeação & Um a nove & 72 & - \\
7. Pré-testes específicos entre sentença e resultado & 9 & 100 \\
8. Treinos do Passo 3 & Um a cinco & 72 & - \\
9. Testes de simetria, transitividade e nomeação & Um a nove & Um a nove e operadores mais, menos e igual & 162 \\
10. Pós-teste geral & & - \\
\hline
\end{tabular}

Nota: *Onde há um traço (-), significa que não havia critério para mudança de fase, pois a sessão era apresentada sem reforçamento por acertos (em extinção).

As tentativas do tipo visual-visual foram compostas de forma idêntica, com a diferença de que o estímulo-modelo ficava exposto na metade superior da tela, dentro do quadrado branco, até que o participante tocasse o estímulo, o que produzia, por meio de um toque na barra de espaço do teclado por parte da experimentadora, a apresentação dos estímulos de escolha, permanecendo durante a escolha do participante. O estímulomodelo, neste tipo de tentativa, podia ser um algarismo impresso, um operador impresso, um conjunto de bolinhas impressas, uma sentença impressa com algarismos ou com conjuntos ou ainda uma palavra impressa referente aos operadores.

\section{Programa de ensino}

Foi construído um programa baseado no paradigma de equivalência de estímulos com a finalidade de mapear o repertório dos participantes referente ao comportamento de subtrair e, a partir da identificação das relações existentes, ensinar as relações consideradas necessárias para cada participante. Ao final de cada treino, eram realizados testes das relações emergentes. O delineamento experimental utilizado pode ser visualizado na Tabela 2 .

\section{Pré-teste}

Anteriormente à aplicação dos procedimentos de ensino, foram aplicados testes para verificar a existência das relações a serem treinadas. Os testes foram compostos de 18 a 36 tentativas distribuídas quase-randomicamente, sendo que cada valor era testado duas vezes em cada relação, com exceção dos testes de nomeação. Consequiências diferenciais não foram planejadas para essa fase e as escolhas, corretas ou incorretas, eram seguidas por um intervalo inter-tentativas de um segundo. Aos participantes era dito que, ao final da sessão, ganharia um item comestível a sua escolha pela participação. Os doces eram organizados sobre uma mesa ao lado e atrás do participante. $\mathrm{O}$ pré-teste geral envolveu todas as relações previstas para o programa de ensino completo, conforme Figura 2.

\section{Treino}

Cada bloco de treino foi composto por nove tentativas, com o ensino de três relações por sessão, apresentadas três vezes cada uma, com a introdução de apenas um estímulo novo por sessão, a partir da segunda sessão. Somente o treino referente aos operadores menos e igual foi composto por 12 tentativas, em uma tarefa composta com apenas dois estímulos como escolhas. Nas demais sessões, foram apresentados três estímulos-escolha em cada bloco. Cada tentativa correta era seguida de uma ficha e de reforçador social (elogios). A ficha foi utilizada porque os participantes haviam passado por um treino prévio, durante o trabalho de Rossit (2004), o qual possibilitou a inferência de que as fichas teriam adquirido função de reforçador condicionado, uma vez que o pareamento de fichas e elogios foi seguido por aumento na frequiência de acertos. Em caso de erro, a ficha e o elogio não eram liberados e uma nova tentativa aparecia em seguida. O critério de desempenho nos treinos foi de $100 \%$ de respostas corretas em um bloco de treino. Ao final dos blocos em que o participante atingia o critério de desempenho, as fichas eram trocadas por um comestível à escolha do participante. Quando o critério não era atingido, era conduzido novamente o mesmo bloco de tarefas, o qual podia ser repetido, no máximo, cinco vezes. Se, mesmo depois disso, os participantes não alcançassem o critério de desempenho exigido, era introduzido um procedimento adicional que consistia em apresentar duas tarefas subseqüentes com a apresentação sucessiva de dois estímulos-modelos e, simultaneamente, dos seus correspondentes estímulos-escolha (Saunders \& Spradlin, 1989).

\section{Pós-teste geral}

Consistiu da reapresentação do pré-teste geral após o término de todos os passos do programa.

\section{Passos de ensino}

Passo 1. O programa de ensino começava com o teste/ treino das relações entre a) os numerais falados, os conjuntos correspondentes e os algarismos para os valores de um a nove; e b) entre os operadores (mais, menos e igual) falados e seus correspondentes em sinais ${ }^{3}$ e palavras impressas. Este primeiro passo consistia, então, da inserção das unidades numéricas envolvidas na operação de subtração em classes equivalentes - os algarismos e operadores que compõem a sentença.

3 Os termos "sinal/sinais" aqui utilizados referem-se aos símbolos que indicam os operadores matemáticos "-" $\mathrm{e}$ "=". 


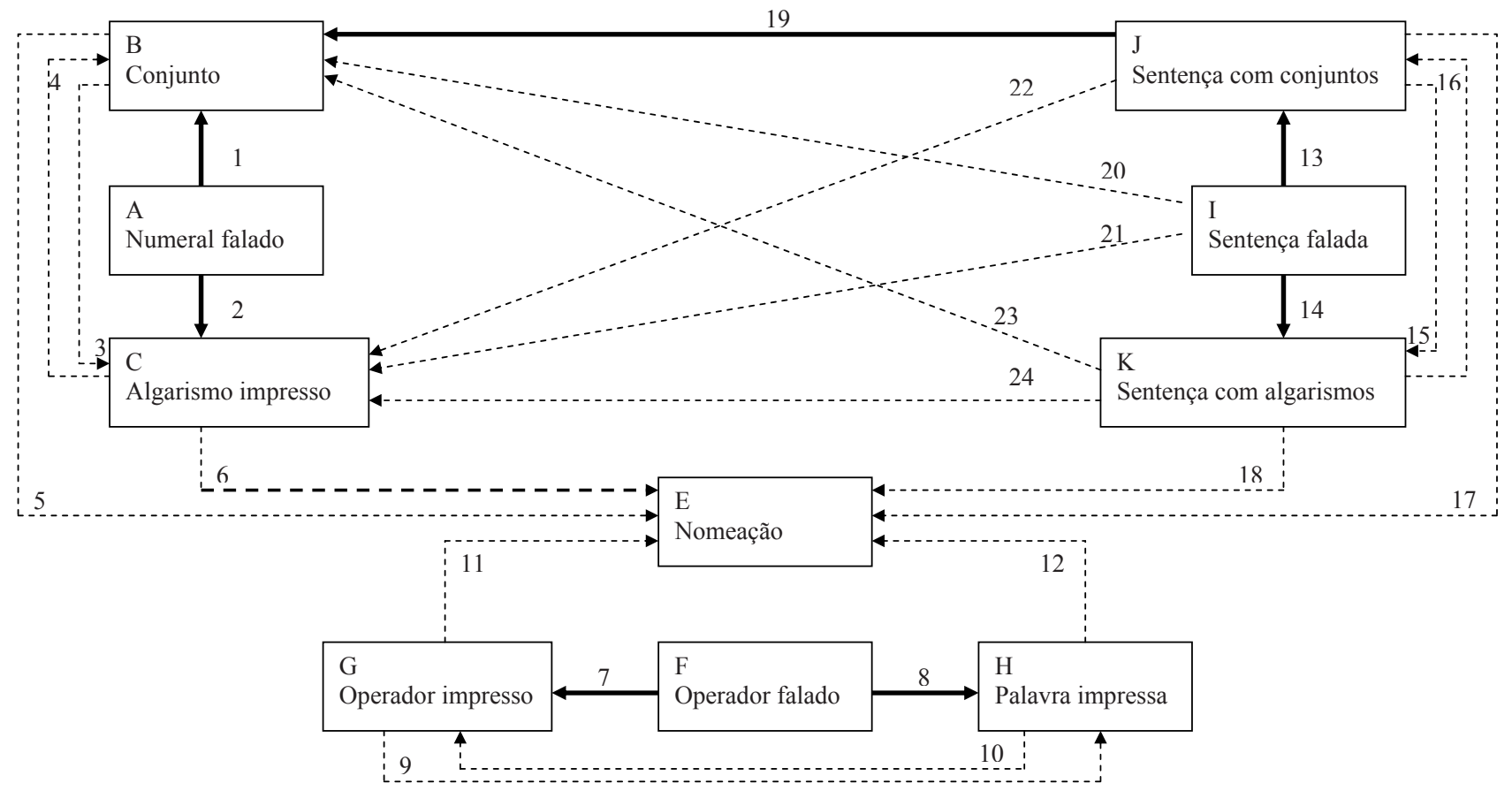

Figura 2. Rede de relações que compõem o comportamento de subtrair. As linhas cheias indicam as relações previstas para treino e as pontilhadas, para testes. Os números indicam a ordem sugerida para a aplicação do programa de ensino.

Passo 2. Em seguida, eram ensinadas as relações entre as sentenças em configurações diferentes - falada, com conjuntos e com algarismos - para os valores de um a cinco. Este passo consistia, portanto, do teste e/ou inserção dos estímulos-sentenças em classes equivalentes. Antes de ensinar diretamente as relações deste passo, um pré-teste específico ${ }^{4}$ foi conduzido, a fim de verificar se as unidades ensinadas anteriormente seriam discriminadas por eles como componentes da sentença de subtração. Temos, portanto, a seguinte ordem: pré-teste, treino e teste. Com o objetivo de inserir diretamente os estímulos em classes equivalentes, o treino neste passo envolveu as relações entre sentença falada (I) e sentença com conjuntos (J) e entre sentença falada (I) e sentença com algarismos (K). Após os treinos das relações IJ e IK, foram conduzidos testes combinados de transitividade e simetria JK e KJ e testes de nomeação de $\mathrm{J}$ e de $\mathrm{K}$.

Passo 3. O passo seguinte consistia do ensino da operação de subtração para os valores de um a cinco, por meio do treino da relação entre a sentença com conjuntos ( $\mathrm{J}$ ) e resultado em conjunto (B) e teste da relação entre sentença e resultado para os valores de um a nove. No treino, as sentenças eram compostas com os conjuntos de bolinhas, apresentadas como modelo, e os conjuntos correspondentes aos resultados das sentenças, apresentados como escolhas. Tivemos nas sessões de testes, respectivamente como modelos e escolhas: sentença falada (I) com resultado em conjunto (B), sentença falada (I) com resultado em algarismo $(\mathrm{C})$, sentença com conjuntos $(\mathrm{J})$ com resultado em algarismo $(\mathrm{C})$ e sentença com algarismos

$4 \quad$ O pré-teste específico sempre se referia às relações que seriam ensinadas no passo em questão, diferindo, assim, do Pré-teste Geral, que testou todas as relações componentes do Programa de Ensino.
(K) com resultado em conjunto (B) - além de sentença com conjuntos $(\mathrm{J})$ com resultado em conjunto $(\mathrm{B})$, sentença com algarismos $(\mathrm{K})$ com resultado em algarismo $(\mathrm{C})$ e a nomeação dos resultados (E') a partir da sentença com conjuntos (J) e da sentença com algarismos (K). A Figura 2 ilustra as relações ensinadas/testadas neste passo.

Nos passos 2 e 3 , os desempenhos dos participantes foram considerados com referência aos numerais de maior valor na sentença de subtração (o numeral à esquerda da sentença) e suas combinações. Por exemplo, quando, na seção de resultados, falar-se em desempenho de $80 \%$ para o valor oito, estarão sendo quantificadas quantas respostas corretas ocorreram nas tentativas do oito menos um a oito menos sete.

\section{Resultados e Discussão}

\section{Pré-teste geral}

Os resultados do pré-teste realizado com todos os participantes estão apresentados na Tabela 3.

\section{Treinos}

\section{Participante MRO}

$\mathrm{O}$ treino foi iniciado pela relação $\mathrm{AB}$ (numeral faladoconjunto), referente ao primeiro passo do procedimento, para os valores sete, oito e nove. Apenas duas sessões foram necessárias para MRO alcançar o critério no treino dessa relação. Seguiu-se, então, o treino da relação IJ (sentença falada-sentença com conjuntos) para os valores seis, sete, oito e nove. Para a maioria das relações desse passo, foi necessária apenas uma sessão de treino para se atingir o critério. 
Tabela 3. Testes aplicados antes (Pré) e após (Pós) os treinos. Os números de 2 a 9 no topo da tabela correspondem aos valores utilizados nas relações apresentadas. A gradação de cores representa os passos do programa, respectivamente Passo 1, Passo 2 e Passo 3. Os dados são apresentados em porcentagens de acertos.

\begin{tabular}{|c|c|c|c|c|c|c|c|c|c|c|c|c|c|c|c|c|}
\hline \multirow{2}{*}{$\begin{array}{c}\text { Valores } \\
\text { MRO }\end{array}$} & \multicolumn{2}{|c|}{2} & \multicolumn{2}{|c|}{3} & \multicolumn{2}{|c|}{4} & \multicolumn{2}{|c|}{5} & \multicolumn{2}{|c|}{6} & \multicolumn{2}{|c|}{7} & \multicolumn{2}{|c|}{8} & \multicolumn{2}{|c|}{9} \\
\hline & Pré & Pós & Pré & Pós & Pré & Pós & Pré & Pós & Pré & Pós & Pré & Pós & Pré & Pós & Pré & Pós \\
\hline $\mathrm{AB}$ & 100 & 100 & 100 & 100 & 100 & 100 & 100 & 100 & 100 & 100 & 50 & 100 & 0,4 & 100 & 100 & 100 \\
\hline $\mathrm{AC}$ & 100 & 100 & 100 & 100 & 100 & 100 & 100 & 100 & 100 & 100 & 100 & 100 & 100 & 100 & 100 & 100 \\
\hline $\mathrm{BC}$ & 100 & 100 & 100 & 100 & 100 & 100 & 100 & 100 & 100 & 100 & 100 & 100 & 50 & 100 & 50 & 100 \\
\hline CB & 100 & 100 & 100 & 100 & 100 & 100 & 100 & 100 & 100 & 100 & 100 & 100 & 100 & 50 & 100 & 100 \\
\hline $\mathrm{BE}$ & 100 & 100 & 100 & 100 & 100 & 100 & 100 & 100 & 100 & 100 & 100 & 100 & 100 & 100 & 100 & 100 \\
\hline $\mathrm{CE}$ & 100 & 100 & 100 & 100 & 100 & 100 & 100 & 100 & 100 & 100 & 100 & 100 & 100 & 100 & 0,4 & 100 \\
\hline IJ & 100 & 100 & 75 & 100 & 100 & 100 & 75 & 100 & 100 & 100 & 66,7 & 91,7 & 78,6 & 100 & 68,7 & 100 \\
\hline IK & 50 & 100 & 100 & 100 & 100 & 100 & 100 & 100 & 80 & 100 & 100 & 100 & 100 & 100 & 100 & 93,8 \\
\hline JK & 100 & 100 & 75 & 75 & 83,5 & 100 & 100 & 100 & 100 & 100 & 83,5 & 100 & 78,6 & 100 & 25 & 100 \\
\hline KJ & 100 & 100 & 100 & 100 & 100 & 100 & 100 & 100 & 60 & 100 & 58,5 & 91,7 & 21,4 & 100 & 75 & 100 \\
\hline JE & 0,6 & 100 & 0,6 & 100 & 0,6 & 100 & 0,6 & 100 & 0,6 & 100 & 100 & 100 & 71,4 & 100 & 62,5 & 100 \\
\hline $\mathrm{KE}$ & 0,6 & 100 & 0,6 & 100 & 0,6 & 100 & 0,6 & 100 & 0,6 & 100 & 83,5 & 100 & 100 & 100 & 100 & 100 \\
\hline IB & 100 & 50 & 75 & 75 & 100 & 100 & 87,5 & 100 & 100 & 90 & 75 & 75 & 85,7 & 100 & 62,5 & 93,8 \\
\hline IC & 50 & 50 & 75 & 75 & 83,5 & 100 & 100 & 100 & 100 & 100 & 100 & 100 & 85,7 & 92,9 & 87,5 & 93,8 \\
\hline JB & 100 & 100 & 100 & 100 & 100 & 100 & 75 & 100 & 90 & 100 & 75 & 100 & 92,8 & 92,4 & 62,5 & 87,5 \\
\hline $\mathrm{KC}$ & 100 & 100 & 100 & 100 & 100 & 100 & 100 & 100 & 100 & 100 & 83,3 & 91,7 & 85,7 & 78,6 & 100 & 87 \\
\hline $\mathrm{JC}$ & 100 & 100 & 100 & 100 & 83,3 & 100 & 87,5 & 100 & 100 & 100 & 66,7 & 91,7 & 71,4 & 100 & 50 & 87,5 \\
\hline $\mathrm{KB}$ & 100 & 100 & 100 & 100 & 100 & 100 & 100 & 100 & 100 & 100 & 91,7 & 91,7 & 85,7 & 85,7 & 87,5 & 93,8 \\
\hline JE' & 100 & 100 & 50 & 100 & 100 & 100 & 100 & 100 & 100 & 100 & 100 & 100 & 100 & 85,7 & 87,5 & 100 \\
\hline KE' & 100 & 100 & 100 & 100 & 100 & 100 & 100 & 100 & 100 & 100 & 100 & 100 & 85,7 & 85,7 & 100 & 100 \\
\hline DUD & & & & & & & & & & & & & & & & \\
\hline $\mathrm{AB}$ & 100 & 100 & 100 & 100 & 100 & 100 & 100 & 100 & 100 & 100 & 100 & 100 & 50 & 100 & 100 & 100 \\
\hline $\mathrm{AC}$ & 100 & 100 & 100 & 100 & 100 & 100 & 100 & 100 & 100 & 100 & 100 & 100 & 100 & 100 & 100 & 100 \\
\hline $\mathrm{BC}$ & 100 & 100 & 100 & 100 & 100 & 100 & 100 & 100 & 100 & 100 & 100 & 100 & 100 & 100 & 100 & 100 \\
\hline CB & 100 & 100 & 100 & 100 & 100 & 100 & 100 & 100 & 100 & 100 & 100 & 100 & 100 & 100 & 100 & 100 \\
\hline $\mathrm{BE}$ & 100 & 100 & 100 & 100 & 100 & 100 & 100 & 100 & 100 & 100 & 100 & 100 & 100 & 100 & 100 & 100 \\
\hline $\mathrm{CE}$ & 100 & 100 & 100 & 100 & 100 & 100 & 100 & 100 & 100 & 100 & 100 & 100 & 100 & 100 & 100 & 100 \\
\hline IJ & 100 & 100 & 75 & 100 & 100 & 100 & 75 & 100 & 100 & 100 & 91,7 & 100 & 100 & 100 & 87,5 & 100 \\
\hline IK & 100 & 100 & 100 & 100 & 100 & 100 & 100 & 100 & 100 & 100 & 91,7 & 100 & 100 & 100 & 87,5 & 93,8 \\
\hline JK & 100 & 100 & 100 & 100 & 100 & 100 & 100 & 100 & 100 & 100 & 100 & 100 & 100 & 100 & 93,7 & 100 \\
\hline KJ & 100 & 100 & 100 & 100 & 100 & 100 & 100 & 100 & 100 & 100 & 100 & 100 & 100 & 100 & 100 & 100 \\
\hline $\mathrm{JE}$ & 0,6 & 100 & 0,6 & 100 & 0,6 & 100 & 0,6 & 100 & 0,6 & 100 & 0,6 & 100 & 0,6 & 100 & 0,6 & 100 \\
\hline $\mathrm{KE}$ & 0,6 & 100 & 0,6 & 100 & 0,6 & 100 & 0,6 & 100 & 0,6 & 100 & 0,6 & 100 & 0,6 & 100 & 0,6 & 100 \\
\hline IB & 0,6 & 100 & 25 & 100 & 66,7 & 100 & 50 & 100 & 40 & 100 & 33,3 & 100 & 28,6 & 100 & 31,3 & 100 \\
\hline IC & 0,6 & 100 & 75 & 100 & 16,7 & 100 & 62,5 & 87,5 & 10 & 100 & 41,7 & 91,7 & 14,3 & 100 & 37,5 & 100 \\
\hline $\mathrm{JB}$ & 50 & 100 & 75 & 100 & 66,7 & 100 & 62,5 & 100 & 50 & 100 & 33,3 & 100 & 42,9 & 100 & 31,25 & 100 \\
\hline KC & 100 & 100 & 100 & 100 & 100 & 100 & 100 & 100 & 100 & 100 & 91,7 & 100 & 100 & 100 & 100 & 100 \\
\hline JC & 100 & 100 & 100 & 100 & 100 & 100 & 100 & 100 & 100 & 100 & 100 & 100 & 92,6 & 100 & 100 & 100 \\
\hline KB & 100 & 100 & 100 & 100 & 100 & 100 & 100 & 100 & 100 & 100 & 100 & 100 & 100 & 100 & 100 & 100 \\
\hline JE' & 100 & 100 & 100 & 100 & 100 & 100 & 100 & 100 & 100 & 100 & 83,3 & 100 & 85,7 & 100 & 75 & 100 \\
\hline KE' & 100 & 100 & 100 & 100 & 100 & 100 & 50 & 100 & 80 & 100 & 83,3 & 100 & 100 & 100 & 87,5 & 100 \\
\hline ROD & & & & & & & & & & & & & & & & \\
\hline $\mathrm{AB}$ & 100 & 100 & 100 & 100 & 100 & 100 & 100 & 100 & 100 & 100 & 100 & 100 & 100 & 100 & 100 & 100 \\
\hline $\mathrm{AC}$ & 100 & 100 & 100 & 100 & 100 & 100 & 100 & 100 & 100 & 100 & 100 & 100 & 100 & 100 & 100 & 100 \\
\hline $\mathrm{BC}$ & 100 & 100 & 100 & 100 & 100 & 100 & 0 & 100 & 100 & 100 & 100 & 100 & 100 & 100 & 100 & 100 \\
\hline CB & 100 & 100 & 100 & 100 & 100 & 100 & 100 & 100 & 100 & 100 & 100 & 100 & 100 & 100 & 100 & 100 \\
\hline $\mathrm{BE}$ & 100 & 100 & 100 & 100 & 100 & 100 & 100 & 100 & 100 & 100 & 100 & 100 & 0 & 100 & 100 & 100 \\
\hline $\mathrm{CE}$ & 100 & 100 & 100 & 100 & 100 & 100 & 100 & 100 & 100 & 100 & 100 & 100 & 100 & 100 & 100 & 100 \\
\hline IJ & 100 & 100 & 75 & 100 & 66,7 & 100 & 87,5 & 100 & 100 & 100 & 50 & 100 & 78,6 & 100 & 87,5 & 100 \\
\hline IK & 100 & 100 & 100 & 100 & 100 & 100 & 100 & 100 & 100 & 100 & 100 & 100 & 92,9 & 100 & 100 & 100 \\
\hline JK & 100 & 100 & 100 & 100 & 100 & 100 & 87,5 & 100 & 80 & 100 & 100 & 100 & 100 & 100 & 87,5 & 100 \\
\hline KJ & 100 & 100 & 100 & 100 & 100 & 100 & 100 & 100 & 100 & 100 & 100 & 100 & 100 & 100 & 100 & 100 \\
\hline $\mathrm{JE}$ & 0,6 & 100 & 50 & 100 & 100 & 100 & 100 & 100 & 100 & 100 & 83,3 & 100 & 71,4 & 100 & 62,5 & 100 \\
\hline $\mathrm{KE}$ & 0,6 & 100 & 100 & 100 & 100 & 100 & 100 & 100 & 100 & 100 & 100 & 100 & 100 & 85,7 & 100 & 100 \\
\hline IB & 0,4 & 100 & 25 & 100 & 33,3 & 100 & 0,4 & 100 & 70 & 100 & 33,3 & 91,7 & 35,7 & 100 & 37,5 & 100 \\
\hline IC & 0,4 & 100 & 50 & 100 & 0,4 & 100 & 50 & 100 & 20 & 100 & 33,3 & 100 & 28,6 & 100 & 50 & 100 \\
\hline JB & 50 & 100 & 50 & 100 & 33,3 & 100 & 75 & 100 & 20 & 100 & 25 & 100 & 42,9 & 100 & 12,5 & 100 \\
\hline KC & 50 & 100 & 0,4 & 100 & 0,4 & 100 & 37,5 & 100 & 40 & 100 & 33,3 & 100 & 21,4 & 100 & 43,7 & 100 \\
\hline JC & 50 & 100 & 75 & 100 & 50 & 100 & 50 & 100 & 0,4 & 100 & 75 & 91,7 & 7 & 100 & 31,3 & 100 \\
\hline KB & 50 & 100 & 0,4 & 100 & 16,7 & 100 & 37,5 & 100 & 20 & 100 & 16,7 & 100 & 21,4 & 100 & 18,8 & 100 \\
\hline JE' & 0,4 & 100 & 0,4 & 100 & 0,4 & 100 & 0,4 & 100 & 20 & 100 & 0,4 & 100 & 0,4 & 100 & 0,4 & 75 \\
\hline KE' & 0,4 & 100 & 0,4 & 100 & 0,4 & 100 & 0,4 & 100 & 0,4 & 100 & 0,4 & 83,3 & 14,3 & 100 & 0,4 & 100 \\
\hline
\end{tabular}

Nos testes específicos entre os treinos, o número de erros é menor para as relações envolvendo os algarismos e as sentenças com algarismos $(25,71 \%$ de erros), do que para as relações envolvendo conjuntos $(74,29 \%$ de erros com conjuntos considerados tanto como modelos quanto como escolhas). Tais erros podem ser explicados pela maior complexidade dos estímulos envolvendo os conjuntos que exige, naturalmente, discriminação de muitos elementos em um único estímulo (Green, 1992; Matos, Hübner \& Peres, 1997; Stromer, McIlvane \& Serna, 1993).

Verifica-se, também, que para esse participante (Tabela 3) os erros vão aumentando ao longo do procedimento, provavel- mente devido ao processo de extinção (Skinner, 1957), já que durante as sessões de testes não havia reforçadores programados e a probabilidade do "erro" era sempre maior $(66,67 \%)$.

O terceiro treino realizado foi o da relação JB (sentença com conjuntos-conjunto) para os valores de um a cinco. O pós-teste específico mostra que esse treino não exerceu influência observável sobre os valores de seis a nove e, devido a isso, foi treinada a relação JB também para tais valores. Além disso, foram executadas sete sessões extras como parte de dois procedimentos adicionais realizados, referentes aos blocos dos valores sete, oito e nove. MRO precisou de mais 
Tabela 4. Testes referentes aos sinais, aplicados antes (Pré) e após (Pós) os treinos. Os sinais menos e igual foram utilizados em testes e treinos. O sinal mais, apenas em testes.

\begin{tabular}{lllllll}
\hline DUD & Menos & & Igual & & Mais & \\
\hline FG & Pré & Pós & Pré & Pós & Pré & Pós \\
FH & 100 & 100 & 50 & 100 & 50 & 100 \\
GH & 0,6 & 100 & 0,6 & 100 & 0,6 & 100 \\
HG & 50 & 100 & 100 & 100 & 100 & 100 \\
GE & 100 & 100 & 100 & 100 & 100 & 100 \\
HE & 0,6 & 100 & 0,6 & 100 & 0,6 & 100 \\
\hline
\end{tabular}

Obs.: Os dados são apresentados em porcentagens de acertos.

de uma sessão de treino para 14 dos 25 blocos de tarefas programados para os valores de seis a nove. Desses 14 blocos, em oito deles $(56 \%)$ os erros cometidos envolveram o estímulo novo (não treinado no bloco imediatamente anterior). Foi realizado um total de 58 sessões, com uma média de duas por bloco de treino.

\section{Participante DUD}

O ensino para este participante começou pelas relações entre os operadores. Foram realizados os treinos para as relações entre o operador falado e o operador impresso (FG) e entre o operador falado e a palavra impressa $(\mathrm{FH})$, para menos e igual. $\mathrm{O}$ desempenho no treino foi alcançado em uma sessão.

Em seguida, realizou-se um teste para as relações envolvendo os operadores (GH, HG, GE e HE; G-operador impresso, H-palavra impressa, E-nomeação) e as porcentagens são de $100 \%$, exceto para as relações de nomeação dos operadores menos e igual (GE) e nomeação da palavra menos (HE) para as quais o participante obteve desempenho de $0 \%$ (Tabela 4). Complementando esse teste, conduziu-se o teste das relações de nomeação das sentenças com conjuntos (JE) e com algarismos (KE), que continuaram com $0 \%$ de respostas corretas, como no pré-teste geral.

Dando prosseguimento ao programa de ensino, foi realizado o pré-teste específico das relações envolvendo as operações de cálculo da subtração (passo 3). As menores porcentagens de acerto são verificadas nas relações entre sentença falada e conjunto (IB) - 50\% para os valores três, oito e nove, $41,7 \%$ para o valor sete e $40 \%$ para o valor seis, com uma média de $69 \%$ de acertos - e sentença falada e algarismo (IC) - $75 \%$ para o valor três, $50 \%$ para os valores dois, cinco, sete e oito, $43,7 \%$ para o valor nove, $40 \%$ para o valor seis e $33,3 \%$ para o valor quatro, com uma média de 44,4\%. Porcentagens de acerto baixas para IB e IC já tinham sido verificadas durante o pré-teste geral. Por outro lado, para a relação JB (sentença com conjuntos-conjunto), na qual DUD havia apresentado porcentagens entre $31,25 \% \mathrm{e}$ $75 \%$, após o treino dos operadores ele apresentou $100 \%$ para a maioria dos valores testados, exceto para o nove $(93,7 \%)$ e para o dois $(50 \%)$.

Os erros apresentados na relação JB (sentença com conjuntos-conjunto) podem ter ocorrido devido a alguma dificuldade em discriminar os conjuntos de bolinhas, pois quando a operação matemática envolvia algarismos impressos, seu desempenho fica, na maioria das vezes, acima de 80\% (Stromer \& cols., 1993). Por esse motivo, iniciou-se o ensino dessa fase do procedimento com a relação entre a sentença falada e o resultado em algarismo (IC).

Foi realizado, então, o treino da relação entre sentença falada e algarismos (IC) para os valores de um a cinco. $\mathrm{O}$ teste imediatamente posterior ao treino dessa relação para os valores de um a nove exibe aumento no desempenho de respostas corretas. A média saltou de $44,4 \%$ para $91,67 \%$. O desempenho não é de $100 \%$ apenas para os valores quatro e seis $(66,7 \%$ e $60 \%$, respectivamente).

Na seqüência, foi realizado o treino da relação IB (sentença falada-conjunto) para os valores de um a cinco. No treino, o critério foi atingido no máximo em duas sessões. O teste imediatamente posterior ao treino dessa relação exibe porcentagens acima de $90 \%$ para todos os valores testados (um a nove), com média de 95,8\%.

\section{Participante ROD}

O treino iniciou-se pela relação entre sentença falada e sentença com conjuntos (IJ), seguido do treino da relação entre sentença com conjuntos e resultado em conjunto (JB). Ambos os treinos foram realizados para os valores de um a cinco.

No treino da relação IJ (sentença falada- sentença com conjuntos) foram realizadas duas sessões apenas para o bloco com as sentenças "2-1, 3-1, 4-1" e uma única sessão para os demais, todos atingindo $100 \%$. Com relação ao treino JB (sentença com conjuntos-conjunto), foi necessária mais de uma sessão apenas para os blocos com as sentenças "2-1, 31, 4-1" (cinco sessões), "3-1, 4-1, 5-1" (três sessões) e "5-4, 2-1, 3-1" (duas sessões). Dos 56 erros cometidos por ROD nesse treino, 33 deles $(58,9 \%)$ parecem ter sido controlados por semelhança entre os estímulos-modelo e escolha (McIlvane, 1998; McIlvane \& Dube, 1992). Houve um aumento acentuado nos acertos do teste imediatamente posterior ao treino, passando-se de uma média no pré-teste de $50 \%$ para uma média, após o treino, de 97,2\%.

\section{Pós-teste geral}

\section{Participante MRO}

$\mathrm{Na}$ Tabela 3, podem ser verificados os resultados dos pós-testes gerais. No passo 1, a participante obtém 100\% de acerto para todas as relações, com exceção do numeral oito na relação CB (algarismo e conjunto) na qual obtém 50\% de acerto. Nos pós-testes dos operadores, mantiveram-se as porcentagens de $100 \%$ que tinham sido obtidas no pré-teste geral para todas as relações envolvendo os operadores.

No passo 2, evidenciou-se uma melhora no desempenho de MRO, apresentando-se índices mais elevados nos póstestes do que nos pré-testes, com exceção da relação entre sentença com conjuntos e sentença com algarismos (JK) para o valor três, na qual obtém $75 \%$ de acertos em ambos os testes.

Nos pós-testes do passo 3, verificam-se, em algumas relações, porcentagens de acertos menores do que nos pré-testes: valores dois (pré-teste 100\%, pós-teste 50\%) e seis (pré-teste 
$100 \%$, pós-teste $90 \%$ ) em sentença falada e conjunto (IB), valor oito (pré-teste $85,7 \%$, pós-teste $78,6 \%$ ) e nove (pré-teste $100 \%$, pós-teste $87 \%$ ) em sentença com algarismos e algarismo (KC) e oito (pré-teste $100 \%$, pós-teste $85,7 \%$ ) na nomeação do resultado da sentença com conjuntos (JE). Na relação entre sentença falada e conjunto (IB), os valores dois, três e sete situam-se abaixo de $80 \%$ no pós-teste. Na relação entre sentença falada e algarismo (IC), o mesmo ocorre para os valores dois e três.

A comparação entre pré e pós-testes gerais permite verificar que os desempenhos são melhores para a maioria das relações ao final da aplicação do programa de ensino, com apenas algumas exceções. Os piores desempenhos no pós-teste geral novamente ocorrem para as relações com os valores sete, oito e nove. Erros para valores de um a cinco ocorrem naquelas relações em que o estímulo-modelo era auditivo.

Os erros apresentados para os valores de um a cinco não persistiram após os treinos que envolveram os valores de seis a nove, com exceção da relação entre sentença com conjuntos e sentença com algarismos (JK) para o valor dois.

\section{Participante DUD}

Ao final de todas as fases do procedimento, por meio da aplicação do pós-teste geral, verifica-se que seu desempenho é de $100 \%$ para a maioria das relações e valores testados, exceto para os valores nove na relação entre sentença falada e sentença com algarismos (IK - 93,8\%), cinco e sete na relação entre sentença falada e algarismo (IC - 87,5\% e $91,7 \%$ ). Percebe-se que, para aquelas relações envolvendo os operadores (nomeação dos operadores - GE - para menos e igual e nomeação da palavra - HE - para o menos) e para a nomeação das sentenças com algarismos (KE) e com conjuntos (JE), nas quais o desempenho é zero mesmo imediatamente após o treino, o desempenho no pós-teste geral é de $100 \%$, o que pode introduzir a hipótese da dificuldade em nomear os operadores quando esses são utilizados sem que estejam inseridos na sentença matemática. Os resultados podem ser visualizados nas Tabelas 3 e 4 .

\section{Participante ROD}

O desempenho do participante no pós-teste geral do passo 1 , referente aos números, atinge $100 \%$ de acertos para todas as relações e valores testados. Resultados semelhantes tinham sido visualizados no pré-teste geral.

Nos pós-testes do passo 2, houve um aumento nas porcentagens de acerto, com o participante obtendo desempenhos de $100 \%$ em todas as relações, com exceção do valor oito na nomeação da sentença com algarismos (relação KE), que passa de $100 \%$ de acertos no pré-teste geral para $85,7 \%$ no pós-teste geral, o que pode ser identificado na Tabela 3.

A Tabela 3 mostra, ainda, que os desempenhos obtidos nos pós-testes do passo 3 estão em $100 \%$ na maioria das relações, sendo exceções as relações entre sentença falada e resultado em conjunto (IB), sentença com conjuntos e resultado em algarismo (JC) e na nomeação do resultado da sentença com algarismos (KE) para o valor sete (respectivamente $91,7 \%, 91,7 \%$ e $83,3 \%$ ) e a nomeação do resultado da sentença com conjuntos (JE) para o valor nove (75\%).
A maior discrepância no desempenho de ROD antes e após a aplicação do programa de ensino ocorre nas relações de nomeação do resultado das sentenças com conjuntos (JE) e com algarismos (KE), que têm porcentagens entre $0 \%$ e $20 \%$ no pré-teste geral e atingem $100 \%$ de acertos no pós-teste geral, exceto para o valor nove em JE e sete em KE.

As porcentagens de acerto do pós-teste geral são maiores que as do pré-teste geral em todas as relações testadas. $\mathrm{O}$ treino de apenas duas relações (IJ - sentença falada e sentença com conjuntos - e JB - sentença com conjuntos e resultado em conjunto) para os valores de um a cinco fez com que os desempenhos para as relações do passo 3 do procedimento, no qual ROD obtém as menores porcentagens de acertos, com médias que variavam de $0 \%$ a 58,3\%, atingissem médias acima de $95 \%$ de acertos para os valores de um a nove. As classes de equivalência foram, portanto, expandidas tanto para novas relações quanto para novos valores (Saunders, Drake \& Spradlin, 1999; Sidman \& Tailby, 1982).

É possível que o treino da relação entre sentença falada e sentença com conjuntos (IJ) tenha influenciado o desempenho nos testes e treinos das relações do passo 3 do procedimento (que envolviam o cálculo da subtração), pois as classes de equivalência entre sentenças com configurações diferentes (sentenças com conjuntos, com algarismos e faladas) foram completadas a partir desse treino. Com a introdução de um novo membro às classes já existentes - os conjuntos de objetos como resultados da operação matemática, inseridos na classe por meio do ensino da relação JB -, houve generalização dessa classe para os outros estímulos (algarismos), ou seja, na presença de uma sentença com conjuntos o participante respondeu tanto para conjuntos de bolinhas quanto para algarismos.

A resposta de nomeação dos resultados a partir das sentenças com conjuntos (JE) e com algarismos (KE) também emergiu (Saunders \& cols., 1999; Sidman \& Tailby, 1982).

\section{Considerações Finais}

Os resultados obtidos no presente estudo corroboram os de estudos anteriores (De Léon, 1998; Figueiredo \& cols., 2001; Prado \& de Rose, 1999; Rossit, 2004; Rossit, Goyos, Nascimento \& Araujo, 2003), que conceberam habilidades matemáticas e de manuseio de dinheiro como redes de relações. A cada novo estudo realizado verifica-se, portanto, que é possível considerar as operações matemáticas como uma rede de relações, facilitando a análise de repertórios acadêmicos e tomadas de decisões sobre o que deve ser ensinado, além da economia de ensino, já que a partir do ensino de algumas relações, outras emergem sem treino direto (Sidman \& Tailby, 1982). Outro fator que deve ser levado em conta é que o mapeamento do repertório do aprendiz permite que a aprendizagem ocorra em ritmo próprio, focalizando no ensino individualizado proposto por Skinner (1968) em "Tecnologia de Ensino".

O procedimento de ensino elaborado foi efetivo na identificação das variáveis que compõem a operação de subtração - os algarismos, os conjuntos, os operadores e as sentenças matemáticas - e pode ser estendido para outras operações aritméticas básicas, tais como a soma e a multiplicação. Para próximos estudos seria interessante que se fizesse o 
controle dos números que são apresentados como resultados das operações, o que poderia facilitar a análise dos erros e, dessa maneira, identificar mais claramente o que pode estar controlando o comportamento do aprendiz de matemática.

Além disso, seria relevante, também, apresentar os resultados das operações matemáticas como modelos em ambiente de MTS $^{5}$, a fim de testar as simetrias em todas as relações possíveis e, assim, identificar inconsistências nas classes que compõem o comportamento matemático.

Quanto à nomeação ${ }^{6}$ dos conjuntos, algarismos e sentenças, os resultados do presente estudo confirmam resultados de estudos anteriores (Sidman \& Tailby, 1982), demonstrando que a nomeação pode emergir a partir do treino em MTS. Já a nomeação dos resultados envolve controles ainda não identificados, sugerindo investigações futuramente promissoras.

O estímulo condicional exerce "controle instrucional" (Cumming \& Berryman citado por Sidman, 1986) ou "contextual" (Sidman, 1986) em ambiente de MTS, conferindo a esses estímulos papel potencialmente instrucional. O uso da instrução (estímulo condicional) em forma de sentença aritmética com conjuntos foi eficaz para outorgar à sentença com algarismos e à sentença com conjuntos a mesma função na seleção das respostas, permitindo que ambas exercessem controle adaptado sobre o comportamento. Partes da instrução foram introduzidas gradualmente, sendo testadas/treinadas primeiramente as relações entre os numerais (numeral falado, conjunto de bolinhas, algarismo e nomeação), seguido do teste/treino dos operadores matemáticos (sinais de menos e igual) e da junção dos numerais e sinais em uma sentença matemática de subtrair, relacionando diferentes tipos de estímulos (sentença falada, com conjuntos de bolinhas, com algarismos e nomeação das sentenças). O último passo foi testar/treinar o cálculo da subtração, por meio da relação entre as sentenças como estímulos-modelo, constituindo a instrução a que se queria chegar no decorrer do procedimento, e os numerais como estímulos-escolha.

Os resultados mostraram que a instrução foi efetiva para todos os participantes. $\mathrm{O}$ ensino de apenas alguns valores (um a cinco) foi suficiente para que o desempenho fosse estendido para novos valores (seis a nove) (Saunders \& cols., 1999; Sidman \& Tailby, 1982). Isso indica que as classes equivalentes que compõem o comportamento de subtrair foram ampliadas e a complementaridade entre números, operadores e a sentença matemática permitiu que emergisse nos repertórios dos participantes o desempenho para a combinação dessas variáveis, gerando o cálculo da subtração. Apenas uma participante necessitou do ensino direto das relações para seis a nove ausentes, não tendo emergido novas relações.

O presente estudo alcançou seu principal objetivo - constituir mais um passo no avanço do ensino de matemática por meio de procedimentos do paradigma de equivalência de estímulos - uma vez que provou ser possível conceber as habilidades aritméticas de subtração como uma rede

5 No presente estudo, os resultados foram apresentados apenas como estímulos-escolha.

6 Tratou-se, geralmente, a nomeação como "simetria" da relação entre um estímulo auditivo e o estímulo visual. Tal uso justifica-se apenas pela comodidade na apresentação dos dados, pois Sidman e Tailby (1982) e outros não o licenciam, além de obviamente se tratarem de tipos diferentes (em complexidade) de discriminação. de relações. Novos estudos devem ser realizados, a fim de que se possa sistematizar o ensino de matemática, como há muito tem sido feito com as habilidades de leitura e escrita. A matemática constitui uma linguagem essencial e o ensino da matemática necessita ser desenvolvido e aprimorado a cada dia. Por que, então, não atentarmos ao progresso científico que se tem buscado diariamente na análise experimental do comportamento? Sugere-se, portanto, que a presente análise, principalmente no tratamento da relação entre estímulos sentença e resultado, soma-se à tecnologia de procedimentos de ensino em equivalência de estímulos com o acréscimo de classes que constituem relações "referente-símbolo" (Sidman, 1994), uma vez que os estímulos que as formam funcionam como símbolos e referentes uns dos outros.

\section{Referências}

De León, N. P. A. (1998). Aquisição de Habilidades Básicas de Matemática através da Formação de Equivalência em Crianças Pré-Escolares. Dissertação de Mestrado, Universidade Federal de São Carlos, São Carlos.

Figueiredo, R. M. E., Silva, L. C. C. da, Soares, U. R. \& Barros, R. S. (Orgs.) (2001). Ensino de Leitura, Escrita e Conceitos Matemáticos. Belém: FIDESA/UNAMA.

Green, G. (1992). Stimulus Control Technology for Teaching Number/Quantity Equivalences [Resumo expandido]. Em Vistoria Austic Children's \& Adult's Association, Inc. Em Conference on the National Association for Autism (pp. 51-64). Melbourne, Austrália.

Kahhale, E. M. S. P. (1993). Comportamento Matemático: formação e ampliação do conceito de quantidade e relações de equivalência. Tese de Doutorado, Universidade de São Paulo, São Paulo.

Matos, M. A., Hübner, M. M. \& Peres, W. (1997). Leitura Generalizada: Procedimentos e Resultados? Em R. A. Banaco (Org.), Sobre Comportamento e Cognição (pp. 470-487). São Paulo: A. R. Bytes Editora Ltda.

McIlvane, W. J. (1998). Teoria da coerência da topografia de controle de estímulos: uma breve introdução. Temas em Psicologia, 6(3), 185-189.

McIlvane, W. J. \& Dube, W. V. (1992). Stimulus control shaping and stimulus control topographies. The Behavior Analyst, 15, 89-94.

Prado, P. S. T. \& de Rose, J. C. (1999). Conceito de número: uma contribuição da Análise Comportamental da Cognição. Psicologia: Teoria e Pesquisa, 15(3), 227-235.

Resnick, L. B., Wang, M. C. \& Kaplan, J. (1973). Task analysis in curriculum design: a hierarchically sequenced introductory mathematics curriculum. Journal of Applied Behavior Analysis, 6, 679-710.

Rossit, R. A. S. (2004). Matemática para deficientes mentais: contribuições do paradigma de equivalência de estímulos para o desenvolvimento e avaliação de um currículo. Tese de Doutorado, Universidade Federal de São Carlos, São Carlos.

Rossit, R., Goyos, C., Nascimento, M. H. \& Araujo, P. M. (2003). Ensino de comportamentos matemáticos: um pré-requisito funcional para pessoas com deficiência mental. Em M. C. Marquezine, M. A. Almeida \& E. D. O. Tanaka (Orgs.), Novos Rumos da Educação Especial, 4 (pp. 77-84). Londrina: Eduel.

Saunders, K. J. \& Spradlin, J. E. (1989). Conditional Discrimination in Mentally Retarded Adults: The Effect of Training the 
Component Simple Discrimination. Journal of the Experimental Analysis of Behavior, 52, 1-12.

Saunders, R. R., Drake, K. M. \& Spradlin, J. E. (1999). Equivalence Class Establishment, Expansion and Modification in Preschool Children. Journal of the Experimental Analysis of Behavior, 71, 195-214.

Sidman, M. (1971). Reading and Auditory-Visual Equivalence. Journal of Speech and Hearing Research, 14, 5-13.

Sidman, M. (1986). Functional Analysis of Emergent Verbal Classes. Em T. Thompson \& M. D. Zeiler (Orgs.), Analysis and Integration of Behavioral Units (pp. 213-245). Hillsdale: Erlbaum.

Sidman, M. (1994). Equivalence Relations and Behavior: a Research Story. Boston: Authors Cooperative, Inc.

Sidman, M. (2000). Equivalence Relations and the Reinforcement Contingency. Journal of the Experimental Analysis of Behavior, 74, 127-146.

Sidman , M. \& Tailby, W. (1982). Conditional discrimination vs. matching-to-sample: an expansion of the testing paradigm. Journal of the Experimental Analysis of Behavior, 37, 5-22.

Skinner, B. F. (1968). The Technology of Teaching. New York: Appleton-Century-Crofts, Educational Division, Meredith Corporation.
Skinner, B. F. (1957). Verbal behavior. New York: AppletonCentury-Crofts.

Spradlin, J. E., Cotter, V. W., Stevens, C. \& Friedman, M. (1974). Performance of mentally retarded children on préarithmetic tasks. American Journal of Mental Deficiency, 78, 397-403.

Stoddard, L. T., Bradley, D. P. \& McIlvane, W. J. (1987). Stimulus control of emergent performances: Teaching money skills. Em J. A. Mulick \& R. F. Antonak (Orgs.), Transitions in Mental Retardation. Vol. 2. Issues in Therapeutic Intervention (pp. 113-149). Norwood: Ablex Publishing Co.

Stoddard, L. T., Brown, J., Hurlbert, B., Manoli, C. \& McIlvane, W. J. (1989). Teaching money skills through stimulus class formation, exclusion and component matching methods: Three case studies. Research in Developmental Disabilities, 10, 413-439.

Stromer, R., McIlvane, W. J. \& Serna, R. W. (1993). Complex stimulus control and equivalence. The Psychological Record, 43, 585-598.

Recebido em 28.08.2006

Primeira decisão editorial em 16.02.2007

Versão final em 21.03.2007

Aceito em 12.02.2008 